\title{
Os Gadgets na Primeira Infância: Mudanças na Subjetividade e na Capacidade de Estar Só
}

\author{
Mariana Trovão de Queiroz
}

\begin{abstract}
Resumo
Após a popularização da internet, é muito comum que as crianças já tenham contato com aparelhos eletrônicos desde muito novas, através de jogos, vídeos e outras mídias. Uma vez que a presença desses gadgets se mostra aparentemente como processo irreversível, o presente estudo busca averiguar, com base na literatura psicanalítica de Freud e Lacan e estudos recentes de áreas correlatas, os efeitos que essa exposição precoce pode acarretar na construção da subjetividade das crianças nascidas após essa difusão, em especial sobre a construção da capacidade de ficar só.
\end{abstract}

Palavras-chave: Gadgets; Psicanálise, Subjetividade.

\begin{abstract}
After internet was made widely popular, contact between children and electronic devices come to happen in early stages of life, e.g., games, videos, and other media. Forasmuch as the presence of these gadgets appears to be an irreversible process, this work intends to evaluate the effects of this precious contact in the building up of the subjectivity in children that are born after this diffusion. This study was based on psychoanalytic literature, namely Freud and Lacan, nonetheless new studies of correlated areas. One of the highlights of this study is how technology affect the capacity of the individual regarding staying alone.
\end{abstract}

Key Words: Gadgets; Psychoanalysis; Subjectivity.

\section{Introdução}

Constitui aspecto essencial no estudo das civilizações a criação de identidades grupais e individuais. A internet, ao que parece, vem para revolucionar esse aspecto. Os grupos agora têm a possibilidade de se formar através de interesses, crenças e outras similaridades não 
apenas territoriais, abrindo novas possibilidades de como o indivíduo se percebe e se identifica. Com infinitas oportunidades de relações com o mais variados tipos de pessoas e grupos, o usuário da rede não fica mais restrito a sua comunidade local, podendo trocar experiências, informações e vivências com pessoas de vários lugares do mundo. Por um lado, isso aproxima as pessoas e incentiva a criação de laços virtuais, principalmente para pessoas interpessoalmente empobrecidas (Graeml, K. S.; Volpi, J. H.; Graeml, A. R., 2004). Porém em excesso, pode ser fator que leva a isolamento social nas relações físicas (Sá, 2012).

Cada vez mais cedo as crianças já estão tendo acesso a vários tipos de mídias, tendo jogos, vídeos e quaisquer outros tipos de entretenimento à sua disposição, com grande facilidade, a qualquer hora do dia. Essas crianças são denominadas nativos ou residentes digitais, em contraponto aos adultos que não cresceram sobre essa influência, referidos como imigrantes ou visitantes digitais (Sfoggia; Kowacs, 2014).

O presente projeto busca investigar se essa disponibilidade contínua dos gadgets possui impactos sobre uma futura capacidade de ficar sozinho. Esta é construída na primeira infância através da internalização da presença da mãe, ou seja, da capacidade do bebê de perceber que a mãe ainda existe mesmo quando distante. Dunker (2017) chama de "tempo de espera" o período em que a criança ficaria sozinha e aprenderia a lidar com a angústia disso, além de simbolizar a presença do outro, em especifico da mãe. Ao que parece, esses intervalos estão sendo preenchidos pelo uso de tablets, smartphones, notebooks, dentre outros aparelhos. Importante ressaltar que durante todo o trabalho o termo mãe se refere a qualquer pessoa que execute a função materna, independentemente de gênero ou consanguinidade, e que essa relação é focalizada por ser constitucional do ser.

A solidão aqui é usada no sentido de lidar com a ausência do outro, sendo esse outro real ou virtual, e não como isolamento social presencial, uma vez que alguém pode estar sozinho fisicamente, porém conectado a várias pessoas através de seus aparelhos eletrônicos. Desta forma, ficar sem esses aparelhos pode resultar em angústia e isso pode se refletir na clínica na como um sintoma contemporâneo na medida em que se apresentar como queixa e causa de sofrimento.

Conforme teorizado por Freud (1920) em Além do princípio do prazer, a simbolização da ausência materna é dada pela angústia sentida pela criança quando a mãe não está presente, e sua alegria quando essa retorna, da mesma forma do fort-da, brincadeira infantil aonde a 
criança arremessa o brinquedo e aguarda ansiosa pela volta desse. Com os gadgets na vida das crianças desde cedo, é suposto que essa angústia que deveria ser sentida em sua integralidade possa ser diminuída em potência, e seus efeitos deveriam ser investigados. Uma possível hipótese a ser levantada acerca disso é a da internet passar a ter o papel de grande Outro. Esse conceito, introduzido por Lacan em 1955, é explicado por Roudinesco (1997) como desejo do Outro, ou seja, o referencial que o individuo segue para guiar suas ações. Geralmente esse papel é atribuído à mãe durante os primeiros anos de vida.

Ao mesmo tempo e paradoxalmente, uma queixa moderna frequente entre os pais é que, com o acesso irrestrito aos gadgets, seus filhos passam cada vez mais tempo utilizando dispositivos eletrônicos, o que afeta a dinâmica e o convívio familiar. Isso já se reflete na clínica, chegando crianças e adolescentes com uma suposta adição aos aparelhos eletrônicos, que preferem passar seu tempo utilizando-os em detrimento do convívio familiar e de suas atividades cotidianas, o que acaba gerando um isolamento voluntário mesmo que na presença de outros.

Uma vez que as novas mídias respondem à demanda do usuário, estando disponíveis o tempo todo e sendo uma presença constante, elas pode se sobrepor à presença física do outro. Dessa forma, o projeto buscou averiguar como isso influi nas relações pessoais. Por consequência de os nativos digitais serem crianças e adolescentes, já que a difusão da internet é um processo relativamente novo, é difícil pesquisar ou prever como isso os afetará em seus relacionamentos amorosos ou até mesmo em suas dinâmicas com seus pares, de forma que o estudo se limita às relações familiares por serem as primeiras e mais diretas.

Importante ressaltar que o panorama sobre o desenvolvimento identitário da criança, feito através das teorias de Freud e Lacan diz respeito ao que é esperado como um ideal, mas não deve ser levado como verdade absoluta uma vez que há muitas outras variáveis que podem interferir nele. Há outros fatores que podem influenciar na construção da subjetividade e na capacidade de ficar sozinho, como número de irmãos, idade com que é inserida em creches ou escolas, e até mesmo a disponibilidade de tempo do cuidador. Por limitação de tempo e também para não distanciarmos do foco principal, não serão exploradas essas variáveis.

\section{Processos de individuação segundo o modelo tradicional}


Uma das questões levantadas nesse trabalho é de que forma se dariam as novas formas de solidão em indivíduos que desde muito cedo em seu desenvolvimento já possuem acesso a dispositivos eletrônicos. Para tentar formular algo sobre o assunto, é necessário entender no modelo tradicional como Freud e Lacan descrevem os processos de construção subjetiva que propiciam alguma capacidade de ficar sozinho, desde o período no qual o bebê e a mãe ainda nem se diferenciam e das primeiras experiências de angustia do bebê quando a mãe se afasta do seu campo de visão.

O início se dá logo no nascimento da criança, aonde ela e a mãe possuem uma relação dita simbiótica no sentido de um completar o outro. Nessa fase, o bebê não se percebe como um ser inteiro. Segue-se então até o período no qual ele já tem a capacidade de se perceber não mais como uma extensão da mãe, mas como um ser completo. No estágio inicial as faltas maternas auxiliam o bebê a se perceber um ser separado da mãe, mas apenas quando ele se perceber uma unidade diferenciada dessa poderá ser falado de uma noção de solidão, que alicerçará uma futura capacidade de ficar sozinho.

Sendo que para Lacan "O nascimento do sujeito é a mais pura relação do nada" (Pizzuti, 2012, p. 16), ao nascer o bebê depende totalmente dos cuidados de alguém que faça a função materna para sobreviver. Em um momento inicial, a mãe é quem supre todas as necessidades do bebê que, ainda sem maturidade para se reconhecer como um ser inteiro, vive em uma espécie de relação simbiótica com ela, como se os dois se configurassem como uma unidade só.

A mãe nessa fase "completa" o bebê na medida que supre o que esse deseja. Embora nesse momento esses desejos estejam muito ligados à satisfação fisiológica da ordem da sobrevivência, Lacan afirma que "aqui encontramos uma coisa que se pode chamar de necessidade, mas que desde logo chamo de desejo, porque não existe estado originário nem estado de necessidade pura" ([1957-1958], 1999, p. 227). Desta forma, segundo Ortigara:

nessa relação, a mãe é para a criança parte dela, criando assim uma relação
simbiótica. Com essa simbiose, ou seja, essa ausência do outro a onipotência da
criança está na relação com a figura materna, vez que a função materna satisfaz as
necessidades alimentares da criança. Assim, a onipotência está constituída nessa
relação, ou projetada na mãe, enquanto objeto de satisfação plena da criança. ( 2015 ,
p.2)

Nesse momento de ilusória completude, a falta da mãe ainda não foi sentida. É através das pequenas ausências maternas que o vazio começa a aparecer e a criança começa a se 
perceber como um ser separado. Isso se dá muito cedo no desenvolvimento e de forma bem sutil, aparecendo como pequenas frustrações e demoras, aonde nem todos os desejos da criança são prontamente atendidos. Segundo Pizzuti:

Desta forma, a mãe amamenta seu filho aplacando sua fome (mal-estar) e ao retirar o seio (satisfação) desperta no bebê uma tensão no sentido de desejar que esse outro (mãe) deseje suprir o que sempre vai faltar. A marca que fica pelo objeto faltante é o que desenha no inconsciente o objeto do desejo. $(2012$, p. 8)

Mesmo com essas falhas, a mãe ainda é para o bebê detentora de todo saber. Ela julga saber o motivo do choro do filho, e dessa forma tenta aplaca-lo. Mesmo que não acerte de primeira, eventualmente o fará. Atendendo assim quem chora, ela significará a experiência para ele, dando um sentido a ela. Aos poucos desta forma, ela vai inserindo o filho no simbólico, termo cunhado por Lacan e definido por Roudinesco e Plon como: "sistema de representação baseado na linguagem, isto é, em signos e significações que determinam o sujeito à sua revelia, permitindo-lhe referir-se a ele, consciente e inconscientemente, ao exercer sua faculdade de simbolização" ([1944], 1998, p. 714)

Nesse processo de ir significando o corpo do filho, a mãe se configura como o Outro da linguagem por inserir o filho nela. Ao longo de sua obra, Lacan atribui diversos significados ao termo "Outro". O referido aqui diz respeito ao papel ocupado pela mãe nos estágios iniciais na vida do filho, que mesmo antes de nascer já tem atribuído a si alguns significantes, que o definirão imaginariamente segundo o desejo da mãe. Quinet, explica que:

O sujeito não 'é' isso ou aquilo. Ele é um vazio, um furo no conjunto da linguagem, deslizando nas cadeias significantes. [...] Mas há alguns significantes do Outro que têm uma força de determinação e se impõem como se fossem uma obrigação que o sujeito deveria acatar para se definir. Estes se apresentam como um 'Tu és...'[...] (2007, p. 7)

É esse Outro que dará elementos para que a criança comece a se constituir como sujeito, através da identificação com os significantes apresentados por ele. Bruder e Brauer explicam que isso ocorre pois:

trata-se do homem como um ser falante, mergulhado em uma cultura antes mesmo de seu nascimento; ele sofre determinações desse sistema simbólico que é a linguagem, e ingressará nessa ordem simbólica a partir da relação com o Outro num primeiro momento, presentificado pela mãe - que vai falar com ele, oferecendo-lhe significantes que o constituirão. (2007, p. 516) 
O processo nomeado por Lacan como Estádio do espelho, ocorrido entre os seis e os dezoito meses de idade, terá papel fundamental no que tange a separar imaginariamente a criança da mãe, a partir da visualização de si mesma como um corpo. Segundo Quinet “o estádio do espelho corresponde à antecipação, através da imagem, da unificação do corpo, antecipação relativa à imaturidade neurológica da criança” (2012, p. 3). Ele corresponde ao momento em que a criança, que até então não tinha nenhuma noção da sua configuração corporal, percebendo seu corpo como algo "despedaçado" ou desconexo, o vê como algo integrado e inteiro. Em Lacan, temos que:

\begin{abstract}
A assunção jubilatória de sua imagem especular por esse ser ainda mergulhado na impotência motora e na dependência da amamentação que é o filhote do homem nesse estágio de infans parecer-nos-á pois manifestar, numa situação exemplar, a matriz simbólica em que o [eu] se precipita numa forma primordial, antes de se objetivar na dialética da identificação com o outro e antes que a linguagem the restitua, no universal, sua função de sujeito. ([1949], 1998, p. 97),
\end{abstract}

Esse processo que o estágio do espelho proporciona de se perceber como sujeito separado é essencial para que a formação da psique da criança, pois nesse momento há a falta, uma vez que a mãe não mais o completa, e consequentemente o desejo. Como exposto por Bruder e Brauer:

\footnotetext{
O que define o sujeito e permite que ele saia da alienação - ou seja, que se separe é aquilo que lhe falta, que constitui o seu desejo. Para que haja a falta, o sujeito vai ser operado por dois significantes, possibilitando, com a separação, que caia um objeto inexistente e alucinado, a (objeto pequeno a). É, então, pela função do objeto a que o sujeito se separa, deixa de estar ligado à vacilação e à indeterminação do ser ao sentido que constitui o essencial da alienação. A separação é a busca da parte perdida do ser. $\mathrm{O}$ objeto a aparece então como aquilo que singulariza o sujeito, pois conota a especificidade de seu desejo. Esta é a maneira esperada, segundo a teoria, para ocorrer a separação. (2007, p. 519)
}

O processo seguinte ao estágio do espelho, seguindo a linha cronológica do desenvolvimento, se dá através de uma brincadeira infantil denominada Fort-da, descrita por Freud ([1920], 2010). Nele, Freud investiga o funcionamento do aparelho psíquico através da observação de uma criança brincando.

Essa criança, um menino de um ano e meio, nunca chorava quando sua mãe o deixava por algumas horas, apesar de ser bastante ligado a ela. A brincadeira dessa criança consistia em apanhar qualquer objeto e arremessar longe para que alguém os achasse. Enquanto o arremessava, emitia um som que Freud identificou como sendo a palavra alemã fort. Freud compreendeu que se tratava de um jogo e que o menino estava brincando de "ir embora" com seus brinquedos. Em uma ocasião, brincando com um carretel de madeira com uma linha 
amarrada, ele jogava o carretel dentro de sua cama, onde não podia vê-lo, e o puxava novamente pela linha, saudando seu reaparecimento com a expressão "da" (ali). A brincadeira de reaparecimento e retorno deixava claro que o prazer maior se ligava ao segundo ato.

Ao ver isso, Freud se indaga o porquê de a criança renunciar ao objeto, do mesmo modo que deixa a mãe ir embora sem protestar. A primeira interpretação possível é que a alegria do reencontro o satisfaria. Porém, em outros casos em que não há a corda para puxar o objeto de volta, essa teoria não funcionaria. $\mathrm{O}$ autor então elabora que a experiência de deixar a mãe ir, além de desagradável, é passiva. Atirando o brinquedo a criança assume o controle da situação, como em um significado desafiador. Freud afirma que as crianças repetem em suas brincadeiras o que lhes causam grande impressão na vida real, ab-reagindo a intensidade da reação e tornando-se donas da situação.

Para suportar esse afastamento materno por algum tempo, a criança já deve se perceber como um outro diferente dela. Na forma de brincadeira ela se apodera desse afastamento, ressignificando a experiência. Mais do que isso, a criança usa da própria criatividade para preencher o tempo, aprendendo a lidar com sua própria presença.

Mesmo como ser diferenciado, o bebê continua ocupando o que é descrito por Lacan como o papel de falo desejado, ou seja, algo que viria a satisfazer a falta do falo original da mãe. Isso é perturbado quando a excitação genital começa a aparecer na criança, causando-lhe fantasias. Esse é o momento do complexo de Édipo, descrito por Freud ([1924], 1976) como o fenômeno central do período sexual da primeira infância, que terá função estruturante à existência e à sexualidade do individuo. Dessa forma, segundo Barreta:

\footnotetext{
esse primeiro tempo do conflito edipiano se inicia não com uma relação dual, e não com o desejo da criança pela mãe, mas com o desejo da criança de ser o objeto de desejo da mãe, o que leva à identificação da criança com o falo imaginário da mãe, o que Lacan chama de narcisismo primário. (2012, p. 161)
}

Esse narcisismo primário será interrompido quando um terceiro entra em cena, retirando da criança a responsabilidade imaginária de preencher a falta da mãe, através da castração. De acordo com Souza “[...] a castração tem o sentido de mostrar para a criança que ela é 'não todo', ou seja, não pode completar a mãe, por isso, esta irá lançar seu desejo para outra coisa" (2012, p.3). Essa castração será realizada pelo pai ou por alguém que faça a figura paterna, introduzindo assim a metáfora do nome do pai. Metáfora pois substitui o significante materno. Segundo Farias e Lima "a metáfora paterna tem a função de dividir o 
desejo materno, ou seja, fazer com que a criança não seja tudo para a mãe, fazendo-se necessário à mãe encontrar o significante de seu desejo no corpo de um homem" (2004, p. 22).

Aqui, caso tudo tenha ocorrido bem, a criança passa da ordem imaginaria para a simbólica, estando inserida em uma cultura, como um ser faltante. Além disso, está lançado o desejo do Outro e o ideal do eu, uma vez que não preenchendo a mãe, a criança se questiona o que é necessário para satisfazer esse Outro demandante.

\section{As Novas Mídias na Subjetividade}

O desconhecimento frente à relação das pessoas com os dispositivos eletrônicos vem sendo muito discutido. A Organização Mundial da Saúde incluiu na $11^{\mathrm{a}}$ edição do CID (Classificação Internacional de Doenças) o "Distúrbio de jogos eletrônicos”, condição na qual a pessoa prefere jogar em detrimento de qualquer outra atividade. Isso porque, embora os jogos tenham ganhado popularidade após a difusão das novas mídias, eles ainda são anteriores a elas, o que torna a discussão sobre seus efeitos e consequências mais antiga. Discussões sobre uma possível adição à tecnologia podem ser observadas em conversas cotidianas entre pais e educadores e tem chegado através de queixa em consultórios.

Ao que tudo indica somos influenciados pelo tipo de conteúdo que temos acesso e a forma que temos acesso a eles. Segundo Nicolaci-da-Costa "algumas tecnologias também podem alterar radicalmente nossos modos de ser (como pensamos, como percebemos e organizamos o mundo externo e interno, como nos relacionamos com os outros e com nós mesmos, como sentimos, etc.)" (2002, p. 193). Os gadgets disponibilizam um acesso imediato a qualquer tipo de conteúdo e interação, fazendo com que não fiquemos restritos apenas a nosso ambiente físico e as pessoas presentes nele.

Da forma como é dado, tendo acesso a qualquer pessoa a qualquer instante, as relações presenciais ficam afetadas, de modo que não é mais necessário interagir com quem está fisicamente conosco quando se tem vontade de compartilhar alguma informação, pedir um conselho, ou indicar algum interesse em comum. As opções de com quem interagir se tornaram mais amplas, não sendo incomum as pessoas que estão literalmente ao nosso lado se sentirem preteridas. Isso se exponencia na relação entre pais e filhos, uma vez que os primeiros perdem muito o controle sobre as interações dos filhos, que tem um mundo de possibilidades em suas mãos. 
Em um artigo, no qual investiga o papel dos celulares na vida de jovens a partir de entrevistas com os mesmos, Nicolaci-da-Costa coloca que:

Os contatos imediatos propiciados pelo uso de atalhos põem por terra diversas barreiras - físicas e simbólicas - e tornam antigas formas de controle obsoletas. Fazem desaparecer os intermediários, as horas e lugares impróprios, ou, ainda, as restrições familiares a um ou outro amigo ou conhecido. Também põem fim à possibilidade de os pais terem conhecimento daquilo que os entrevistados desejam manter distante de seus ouvidos. (2004, p. 165)

Alguns fatores da própria constituição familiar moderna propiciam essa maior individualidade e autonomia dos jovens. Nicolaci-da-Costa os aponta como:

[...] uma consequência dos novos modos de produção industrial, dos processos de secularização das sociedades, das migrações das populações rurais para os recémcriados centros urbano industriais, do rompimento com as raízes comunitárias, do anonimato e isolamento urbanos, etc. (idem)

Isso pode ser ilustrado pelo artigo de Biasoli-Alves, que embora compare grupos de crianças nascidas entre 1930 e 1980, já mostra essa tendência de recolhimento da família ao ambiente familiar, em detrimento da vida em comunidade, ao longo do tempo:

Primeiramente. o espaço físico em que as crianças dos três grupos passaram a infância é, num primeiro momento, caracterizado como amplo e altera-se chegando a bem limitado - da liberdade de se deslocar de um canto a outro da cidade para a restritividade da casa e ambientes pequenos a ela afins. Desaparece a rua como ponto de encontro e brincadeiras: a conotação dada ao ambiente doméstico sofre, ao mesmo tempo, alteração de significado em relação especialmente ao seu uso pela criança. (1997, p. 41)

Um estudo de Benincá e Gomes investiga a concepção de família para três gerações de mulheres (avó, mãe e filha) e também confirma essa tendência:

\begin{abstract}
A terceira geração substituiu os padrões da família por um sistema de referências particular, diferenciando-se significativamente das duas anteriores. Esta geração mostrou-se mais crítica, expressando posições de respeito à liberdade de escolha e opinião, e de estímulo à sensibilidade dos filhos. A formação para o trabalho perdeu em importância para a afetividade e autoconfiança e, principalmente, liberdade e autonomia para a realização pessoal, independentemente de planos preestabelecidos pelos pais. Efetivou-se a prática da compreensão e apoio familiar pelo respeito às necessidades individuais, bem como a preocupação com o ajustamento emocional e social dos filhos. (1998, p. 193)
\end{abstract}

As famílias estendidas, ou seja, lares compostos por avós, tios, primos, etc., foram se tornando mais raros e sendo substituídos pelas famílias nucleares, aonde também há uma tendência a um número reduzido de filhos. Segundo Ramos e Nascimento "Quando esta se tornou nuclear (pais e filhos), houve um superinvestimento afetivo dos primeiros em relação aos segundos. Os filhos passam a ser alvos dos amores paternos, merecendo todos os cuidados e proteções que estes últimos podem oferecer.” (2008, p. 468) 
Importante ressaltar que esse mal estar causado por mídias novas não é inédito e já se deu de varias formas, iniciando-se inclusive com a própria televisão. O trecho a seguir, de Setzer ilustra bem o medo de que o aparelho televisor distanciasse os membros da família ao invés de reuni-los para um diálogo comum:

A televisão isola as pessoas por natureza. Se uma família está reunida vendo TV, cada membro está em seu estado de sonolência (cf. item 1) e não há conversa pois ela atrapalha o som ouvido do aparelho. Uma de minhas tias queixava-se há muitos anos de não poder mais visitar amigos durante o horário das novelas, pois não havia possibilidade de conversar com eles. (2014, item 13)

Outra crítica surge quando começa a se popularizar um número múltiplo de aparelhos pelas casas, como aponta Pinto:

A presença de um segundo receptor de TV (e por vezes mais), sendo a via mais fácil para evitar conflitos de preferencias ou simplesmente para ver televisão com mais comodidade, levou a que a sala de estar (ou a cozinha) tenha deixado de ser, num número elevado de casos, o espaço de encontro e de interação, que o visionamento dos programas televisivos apesar de tudo proporciona. (2005, p. 64)

\subsection{Mudanças Subjetivas}

No modelo familiar tratado nesse estudo, o uso continuo dos gadgets pelos filhos muitas vezes é sentido pelos pais como intrusivo, como algo que afasta a convivência doméstica e distancia seus membros. Nesse trabalho em específico, pelas teorizações serem sobre a interferência das novas mídias em processos iniciais de identificação, se fala da geração alpha ${ }^{1}$, que nasceu (e está nascendo) já no mundo ultraconectado. Essa geração compreende crianças que nasçam entre 2010 e 2024, o que acarreta estarmos falando de um fenômeno que está acontecendo no momento e ainda não chegou ao fim, de forma que aparece pouco na clínica.

Embora essa geração escolhida seja primordial nesse estudo, não significa que as possíveis questões clinicas não estejam em andamento em gerações anteriores, uma vez que a difusão dos gadgets é algo que ultrapassa faixas etárias e condições econômicas, já que não é necessário que os aparelhos sejam de última geração para que que o acesso ocorra.

\footnotetext{
${ }^{1}$ Há questões controversas sobre qual a geração que já nasceu totalmente imersa na cultura digital, variando de acordo com a fonte pesquisada. Há autores que afirmam que na geração $\mathrm{Z}$ (a anterior à alpha) todos esses fenômenos já podem ser observados. Porém, por ela ter início com os nascidos em meados de 1998, quando os gadgets ainda não estavam tão difundidos, optamos pela geração alpha na qual todos os nascimentos já se dão no mundo ultraconectado.
} 
A queixa recorrente entre os visitantes digitais (pais), ou seja, pessoas que nasceram anteriormente a difusão dos gadgets, geralmente, é a da falta da partilha de conteúdo e de convivência familiar em seus domicílios, que supostamente estão sendo substituídas pela individualidade proporcionada pelos aparelhos. Em um tempo anterior, quando nas casas comumente havia apenas uma televisão para todo a família, a reunião era em torno de uma só tela, e portanto um só conteúdo, o que permitia debates direcionados. Com os aparelhos móveis, mesmo reunidas no mesmo ambiente, cada pessoa tem acesso ao seu próprio conteúdo de interesse.

Com a difusão do computador em um momento inicial, e depois dos celulares, tablets, Ipads e outros aparelhos que permitem o acesso ao mundo online, entra em cena uma nova questão que contribui para que as atenções se concentrem neles: além de toda a privacidade ${ }^{2}$ e maior interferência sobre o conteúdo consumido, o sujeito deixa de ser apenas um expectador (nos moldes anteriores do cinema/televisão) e passa a interagir ativamente com os gadgets.

\subsection{Do Sujeito/Espectador ao Sujeito/Assujeitado}

No modelo de espectador concebido e estudado especialmente até a virada do século, ao assistir à televisão ou especialmente no cinema, o sujeito se situava numa postura passiva ao receber as imagens projetadas, como explica Fantini: "Sentados, com a motricidade quase suspensa, com investimento excessivo nas funções visuais e auditivas, emulamos nossa condição primeira de imobilidade como bebês, excluídos da ação, restritos a assistir àquilo que quem nos cuida nos permite ver". $(2015$, p. 5)

Os aspectos físicos, como a posição das cadeiras, a tela grande e com a resolução o mais nítida possível no cinema criam as condições para que o espectador se sinta imerso na história mostrada. Por mais que o telespectador dê um sentido pessoal àquilo que vê e crie suas próprias interpretações sobre o que virá a seguir, ele não tem controle sobre o que será exibido, tendo que adequar-se à narrativa. A história já está pronta quando ele tem acesso a ela.

\footnotetext{
${ }^{2}$ Se em um tempo anterior aos celulares para se comunicar de maneira rápida com alguém era necessário ligar em um telefone fixo por exemplo, e correr o risco de outra pessoa atender e ter que encaminhar para quem se desejava falar, hoje esses intermediários não são mais necessários. Dessa forma, me refiro à privacidade no sentido de não ser mais necessário pessoas ao redor saberem com quem se fala, sobre o que se fala ou que tipo de conteúdos são acessados (como quando havia apenas um computador na residência e todos tinham acesso à ele).
} 
Com a televisão, mesmo que o sujeito não interaja ativamente com o roteiro, ele já não se encontra mais tão imerso no que lhe é oferecido, uma vez que ele pode trocar de canal caso o conteúdo exibido não esteja lhe agradando. O tipo de produção audiovisual também não é o mesmo. Embora filmes também sejam exibidos na televisão, nela o telespectador possui uma vasta gama de opções do que assistir, como novelas, programas de auditório e telejornais que não exigem o mesmo envolvimento de quem assiste. Os intervalos comerciais também funcionam como quebras dessa imersão. Machado explica que:

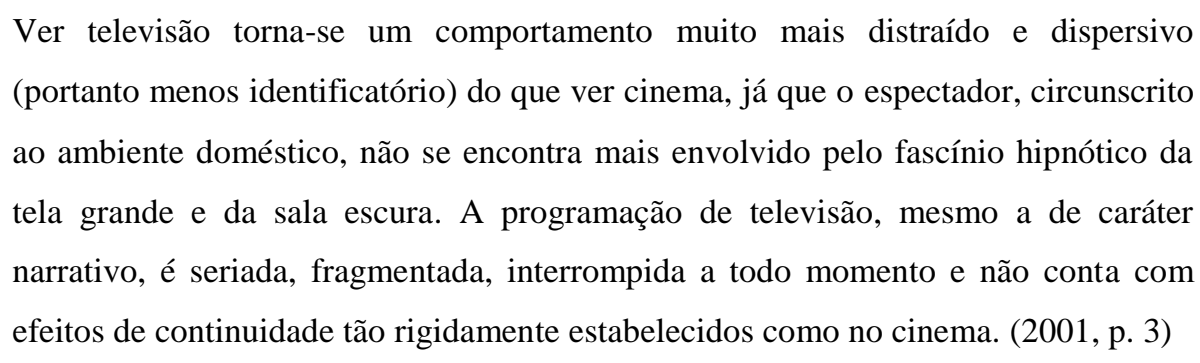

Apesar de um maior envolvimento do sujeito, na televisão ele ainda se encontra no papel do telespectador assim como no cinema, no que diz respeito à sua passividade perante o que é apresentado. Cito Fantini: "No cinema tradicional não esperamos conscientemente interferir na história do filme, ao contrário, nos games e no ciberespaço, esperamos cada vez mais interferir diretamente no andamento da história.” (2013, p. 12)

Os games, tanto os de console quanto os acessados por gadgets, possuem um caráter bem mais interativo no sentido de o jogador personalizar como vai ser a experiência e seus rumos. Ao poder ter escolhas em tempo real sobre as narrativas, personagens e outros aspectos que compõem os games, o sujeito se sente compondo a história de acordo com sua vontade. Além disso o fato de várias pessoas jogarem e compartilharem suas experiências acaba criando uma espécie de comunidade, mesmo que virtual, que dá a sensação de pertencimento a seus membros. Dessa forma, eles se tornam sujeitos assujeitados, como explica Fantini:

O conceito de assujeitamento surge de forma organizada na Análise do Discurso de
linha francesa, especialmente Pêcheux que retoma as ideias de Althusser, definido
como um processo que consiste em fazer com que o indivíduo tenha a impressão de
que é senhor de sua própria vontade e seja levado a ocupar seu lugar, identificando-
se ideologicamente com grupos ou classes de uma determinada formação social. (p.
7)

Entretanto, essa noção de ser "senhor de sua própria vontade" é uma ilusão dada ao sujeito, uma vez que mesmo que suas interações com a máquina mudem os rumos da história em tempo real, essa máquina já foi programada previamente. Isso quer dizer que o sujeito tem 
escolha, mas dentro das opções dadas pelo jogo. Ele pode customizar seu personagem do jeito que desejar, mas não é possível fazê-lo executar ações que não tenham sido incluídas pela máquina em seu repertório. Ele pode determinar o caminho que quer percorrer, mas se o jogo tiver colocado uma porta que não pode ser aberta, terá que recalcular a rota a ser percorrida. Cito Machado:

\begin{abstract}
Por essa razão, a "história" que se desenrola na tela nunca se repete exatamente da mesma maneira, mas também jamais pode enveredar por caminhos que não estão previsto s no programa. Como num jogo de xadrez, o interator domina as peças e tem autonomia para adotar a estratégia que lhe parecer mais adequada para chegar ao xeque-mate, mas só pode atuar dentro das regras determinadas pelo algoritmo do jogo. (p. 10)
\end{abstract}

Assim como nos vídeo games, aonde a pessoa tem diversas alternativas, porém estando essas dentro de um espectro dado pelo programador do jogo, na internet a noção do internauta de ter total decisão sobre os conteúdos que acessa também não é completamente real. Não estamos livres da influência dos algoritmos ${ }^{3}$, que coletam informações sobre os interesses do usuário para posteriormente personalizar a rede. Pariser explica:

\begin{abstract}
A maior parte das pessoas imagina que, ao procurar um termo no Google, todos obtemos os mesmos resultados - aqueles que o PageRank ${ }^{4}$, famoso algoritmo da companhia, classifica como mais relevantes, com base nos links feitos por outras páginas. No entanto, desde dezembro de 2009, isso já não é verdade. Agora, obtemos o resultado que o algoritmo do Google sugere ser melhor para cada usuário específico - e outra pessoa poderá encontrar resultados completamente diferentes. Em outras palavras, já não existe Google único. (2012, p. 6)
\end{abstract}

Através das páginas acessadas, buscas realizadas, compras feitas pelo usuário, os algoritmos identificam que tipo de informação pode interessar a cada pessoa, direcionando-a a conteúdos aos quais ele provavelmente se engajará. Ainda segundo Pariser: "Cada vez mais, o monitor do nosso computador é uma espécie de espelho que reflete nossos próprios interesses, baseando-se na análise de nossos cliques feita por observadores algorítmicos.” (2012, p. 7)

\title{
3.3 As novas mídias e o grande Outro
}

Em um primeiro momento deste trabalho, identificamos a mãe como o primeiro grande Outro, por ser quem oferece significantes que constituirão o sujeito e o insere no sistema simbólico que é a linguagem. Para além disso, o Outro pode ser entendido também

\footnotetext{
${ }^{3}$ Algoritmos podem ser entendidos como um conjunto de passos ordenados para a execução de uma tarefa

${ }^{4}$ PageRank não é o único algoritmo que o Google utiliza, mas é o primeiro e mais conhecido. Os algoritmos estão sempre sendo atualizados e nem sempre são divulgados para o público.
} 
como campo social, ou seja um lugar que não se identifica com o pequeno outro. Dunker (2016) define o grande Outro como "lugar simbólico de onde eu recebo minha própria mensagem de maneira invertida", ou seja, algo no qual o sujeito por um lado sabe ter participação, mas não se reconhece totalmente. Ainda segundo Dunker: "eu me relaciono com aquilo como um enigma, como algo que me representa mais além de mim mesmo".

Desta forma, a linguagem e até a diferença sexual podem atuar como Outro no sentido de estarem em um principio de alteridade radical, ou seja, de serem algo para além de nós mesmos e para além do pequeno outro, que nada mais é que nosso semelhante. As novas mídias além de estarem nesse lugar de alteridade, também possuem informações sobre nós, e nos sugere e dá mais elementos para nos identificarmos e nos constituirmos, de forma que podemos pensar na hipótese de elas também atuarem como um "grande Outro". Cito Ravasio:

O Outro é o 'tesouro dos significantes', onde habita a verdade do sujeito, em que só é possível na forma de um meio-dito, sendo um saber sobre o sujeito que inclui um não saber, marcando a impossibilidade de apreensão completa, marcada pelo engano, pelo equívoco. (2016, p. 156)

A seguir, levanto algumas considerações.

\section{CONSIDERAÇÕES FINAIS}

Uma vez percorrido o caminho do processo de individuação do sujeito na teoria psicanalítica de Freud e Lacan, e tendo levantado algumas das possíveis mudanças que as novas mídias podem causar na subjetividade de quem as acessa, pretendo revisitar a primeira parte do trabalho, de forma a reacessar os processos constituintes do sujeito na infância, pensando em como eles podem ocorrer com a presença das novas mídias.

Desde o inicio do trabalho chamo a atenção para uma possível nova forma de solidão, uma vez que os gadgets geralmente são usados de forma individual, sendo corriqueiro ver pessoas de qualquer faixa etária sozinhas, imersas em seus aparelhos. Da mesma forma, uma pessoa pode passar um final de semana inteiro sozinha em sua casa, sem ter saído ou recebido nenhuma visita e mesmo assim ter conversado e interagido o tempo todo com pessoas através de seus aparelhos eletrônicos. Estaria mesmo ela sozinha?

Os aparelhos eletrônicos vêm sendo usados pelos cuidadores para distrair e acalmar as crianças desde a mais tenra idade. Se há necessidade de realizar uma tarefa doméstica, atender um telefonema ou mesmo de tomar banho, as telas se mostram uma alternativa fácil e eficaz para prender a atenção de seus filhos. Porém, além de preencher tempos nos quais a criança 
não tem nenhuma atividade para realizar, os dispositivos eletrônicos podem também estar funcionando de forma a aplacar a angústia desses. Por exemplo, as pequenas ausências maternas podem passar desapercebidas quando a atenção da criança está focada em um gadget.

São nessas pequenas ausências que o vazio pode aparecer e a criança começa a se perceber como separado da mãe. Apenas se entendendo como um ser separado e inteiro é possível estar sozinho sem altos níveis de angústia. Uma hipótese que levanto é a de que, mesmo que de alguma forma a criança consiga se separar e se diferenciar da mãe, os aparelhos eletrônicos podem funcionar como "muletas", de forma a facilitar o processo. Desta forma, a criança conseguiria suportar a angustia de uma ausência da mãe, desde que haja um gadget para auxiliá-la nisso.

Essa afirmação nos leva a pensar o lugar que as novas mídias talvez possam desempenhar na vida das pessoas. Por exemplo, o que explica a angustia e inquietude de uma pessoa quando a bateria de seus aparelhos eletrônicos acaba ou quando por algum motivo ela não pode acessa-lo?

De certa forma, as novas mídias estão sempre demandando nossa atenção. Seja por uma luz que acende, um som ou uma vibração, os gadgets mostram quando uma atividade ocorre, nos notificando que há algo novo a ser visto. Com a velocidade com a qual as informações aparecem e se atualizam, ficar por um curto período de tempo longe das telas pode implicar na sensação de estar de fora da comunidade, uma sensação de perda do laço social. Uma queixa recorrente entre pais é a dificuldade de trazer os filhos de volta à realidade off-line, afastando-o dos aparelhos. Afinal, o que salta mais à atenção, um chamado da mãe ou a notificação de uma tela?

Além das demandas cotidianas, como um chamado para uma tarefa, os pais geralmente também esperam que os filhos atendam a um outro tipo de demanda, que é o inventário de características que foi idealizado e pensado para eles quando nasceram ou estavam sendo gestados. Esse inventário vem de elementos inscritos na cultura e vão se replicando através das gerações. É ele uma das bases da constituição do ideal do Eu da criança, uma vez que para a criança existe a ameaça de perder o amor dos pais caso não atenda a suas expectativas. Assim:

A esse ideal do Eu dirige-se então o amor a si mesmo, que o Eu real desfrutou na infância. $\mathrm{O}$ narcisismo aparece deslocado para esse novo Eu ideal, que como o 
infantil se acha de posse de toda preciosa perfeição. Aqui, como sempre no âmbito da libido, o indivíduo se revelou incapaz de renunciar à satisfação que uma vez foi desfrutada. Ele não quer se privar da perfeição narcísica de sua infância, e se não pôde mantê-la, perturbado por admoestações durante seu desenvolvimento e tendo seu juízo despertado, procura readquiri-la na forma nova do ideal do $\mathrm{Eu}$. O que ele projeta diante de si como seu ideal é o substituto para o narcisismo perdido da infância, na qual ele era seu próprio ideal. (FREUD, 1914, p. 27)

Além dos pais, outras instâncias atuam na formação desse ideal. No mesmo texto de Freud:

Pois a incitação a formar o ideal do Eu, cuja tutela foi confiada à consciência moral, partiu da influência crítica dos pais intermediada pela voz, aos quais se juntaram no curso do tempo os educadores, instrutores e, como uma hoste inumerável e indefinível, todas as demais pessoas do meio (o próximo, a opinião pública). (p. 29)

Desta forma, podemos pensar que uma criança, hoje, e como nunca, desde pequena é exposta aos meios de comunicação e especialmente às novas mídias. $\mathrm{O}$ meio digital também nos apresenta demandas, do tipo estarmos sempre engajados e a par do que está acontecendo para não perdermos informações, sejam essas um vídeo novo ou uma nova missão em algum jogo. Além disso, pode ser que o conteúdo do que está sendo acessado pelas crianças, que é um ponto passível de estudos, influencie de algum modo na construção do ideal do eu.

Isso poderia reforçar a ideia levantada anteriormente de as novas mídias estarem desempenhando o lugar do Outro, uma vez que oferece os elementos para a constituição do sujeito e apresenta demandas as quais se busca atender. Isso de forma alguma altera a importância da mãe desse lugar, mas talvez seja algo que se some a ela, uma vez que o papel do Outro pode ser desempenhado por mais de uma instância.

Ressalto que essas hipóteses não vêm acompanhadas de juízo de valor, afinal não sabemos se essas interferências viriam no sentido de atrapalhar os processos ou apenas ser uma forma alternativa de vivencia-los.

Por exemplo, sabe-se que a importância de a criança passar pelo Fort da no sentido de se apropriar da experiência da ausência materna. Mas nada impede que um jogo em um gadget consiga reproduzir a experiência, simbolizando o conflito de presença e ausência materna de alguma forma através de uma experiência lúdica. Inclusive, abre-se um campo de pesquisa sobre que tipos de conteúdos e atividades podem ser propostos nas novas mídias no sentido de auxiliar esses processos descritos. 
Uma vez que atualmente crianças de seis a dezoito meses já são expostas às novas mídias, sendo essas vídeos ou mesmo jogos menos sofisticados que exigem poucos comandos, pode ser que entretidas com a tela, passem - talvez - de outra maneira pelo que Lacan chama estádio do espelho e se apropriem do corpo e da autoimagem corporal de maneira diferente.

Tudo isso que levanto possivelmente só poderá ser observado depois de já ter ocorrido, ou seja, quando as crianças que estão passando por isso se tornarem adultas e chegarem a clínica. Por enquanto, o que chega é a queixa dos pais que se sentem preteridos pelos aparelhos eletrônicos. O que parece estar acontecendo é que a angústia anteriormente sentida pelos filhos na ausência dos pais pode estar sendo diminuida pelo uso de gadgets e dessa forma se volta para os próprios pais, se transformando em uma espécie de angústia da ausência do filho.

Há várias formas de encarar o papel que a tecnologia tem desempenhado na vida das pessoas, principalmente na das crianças. Há uma visão catastrofista, na qual se acredita que as novas mídias prejudicarão os processos psicológicos, cognitivos e sociais das pessoas. Há a visão entusiasta, de que a tecnologia traz apenas melhorias e mais desenvolvimento. Há ainda a visão de que é só uma questão técnica, como um fenômeno que está acontecendo e cabe apenas às pessoas se adaptarem a eles, sem que essas influenciem subjetivamente elas. A visão que cabe a psicanálise é a de procurar entender quais os possíveis desdobramentos dessa relação que vem sendo estabelecida com o mundo digital, promovendo estudos que atuem de forma a antecipar e prever possíveis modificações subjetivas e de que forma se pode lidar com elas.

\section{REFERÊNCIAS BIBLIOGRÁFICAS}

AAP Announces New Recommendations for Children's Media Use. American Academy of Pediatrics. 2016. Acessado em 29 de julho de 2017, disponível em: https://www.healthychildren.org/English/news/Pages/AAP-Announces-New-

Recommendations-for-Childrens-Media-Use.aspx

BARRETTA, João Paulo Fernandes. O Complexo de Édipo em Winnicott e Lacan. Psicol. USP, São Paulo, v. 23, n. 1, p. 157-170, mar. 2012 . Acessado em 07 de julho de 2018, disponível em http://www.scielo.br/scielo.php?script=sci_arttext\&pid=S0103$65642012000100008 \& \operatorname{lng}=$ pt\&nrm=iso 
BENINCA, Ciomara Ribeiro Silva; GOMES, William B. Relatos de mães sobre transformações familiares em três gerações. Estud. psicol. (Natal), Natal , v. 3, n. 2, p. 177205, Dec. 1998 . Acessado em 21 de Setembro de 2018, disponível em http://www.scielo.br/scielo.php?script=sci_arttext\&pid=S1413-

294X1998000200002\&lng=en\&nrm=iso

BIASOLI-ALVES, Zélia Maria Mendes. Famílias brasileiras do século XX: os valores e as práticas de educação da criança. Temas psicol., Ribeirão Preto , v. 5, n. 3, p. 33-49, dez. 1997 . Acessado em 27 de Setembro de 2018, disponível em http://pepsic.bvsalud.org/scielo.php?script=sci_arttext\&pid=S1413-

389X1997000300005\&lng=pt\&nrm=iso

BRUDER, Maria Cristina Ricotta; BRAUER, Jussara Falek. A constituição do sujeito na psicanálise lacaniana: impasses na separação. Psicologia em Estudo, Maringá, v. 12, n. 3, p. 513-521, set./dez. 2007. Acessado em 07 de julho de 2018, disponível em http://www.scielo.br/pdf/pe/v12n3/v12n3a08.pdf

CARTER, Christine. The complete guide to generation alpha, the children of millennials. Washington: Forbes, 21 dez. 2016. p. 1-3. Acessado em 29 de outubro de 2018, disponível em: $\quad$ https://www.forbes.com/sites/christinecarter/2016/12/21/the-complete-guide-togeneration-alpha-the-children-of-millennials/\#6b4ba90f3623

CESAROTTO, Oscar A.; FANTINI, João Angelo. A Metodologia empregada na Psicanálise em Extensão. 2017, inédito.

DUNKER, Christian. Um Retorno à Freud In: Um Retorno a Freud.1 ed.Campinas : Mercado das Letras, 2008, v.1, p. 107-122. Acessado em 24 de maio de 2018, disponível em http://pepsic.bvsalud.org/scielo.php?script=sci_arttext\&pid=S0102-73952007000100005

DUNKER, Christian. O que é o Grande Outro para Lacan? Falando nIsso 56. (5m34s) 2016. Acessado em 02 de Outubro de 2018, disponível em https://www.youtube.com/watch?v=WUCG06nbbBY

DUNKER, Christian. Intoxicação Digital Infantil, 2017. Acessado em 04 de julho de 2017, disponível em: http://brasileiros.com.br/2017/02/intoxicacao-digital-infantil/

DUNKER, Christian. O que você pensa sobre o uso da tecnologia na transmissão de um saber?, 2017. Acessado em 04 de julho de 2017, disponível em: http://www.escutatorio.com/blog/2017/6/14/o-que-voc-pensa-sobre-o-uso-da-tecnologia-natransmisso-de-um-saber-por-christian-dunker

FANTINI, João Angelo. A Invenção do Espectador e as Novas Subjetividades: da Renascença ao Cinema 3D, dos Games ao Ciberespaço In: Semiótica Psicanalítica: Clínica da Cultura.1.a ed.São Paulo : Iluminuras, 2013.

FARIAS, Cynthia Nunes de Freitas.; LIMA, Glaucineia Gomes. A relação mãe criança: esboço de um percurso na teoria psicanalítica. Estilos clin., São Paulo , v. 9, n. 16, p. 1227, jun. 2004 . Acessado em 30 de abril, disponível em http://pepsic.bvsalud.org/scielo.php?script=sci_arttext\&pid=S1415-

$71282004000100002 \& \operatorname{lng}=$ pt\&nrm=iso 
FARIAS, Gilberto, \& SANTANA, Eduardo. Introdução à Computação. Cap. 5.1: Algoritmos. (S/D). Acessado em 28 de Outubro de 2018, disponível em http://producao.virtual.ufpb.br/books/camyle/introducao-a-computacaolivro/livro/livro.chunked/index.html

FREUD, Sigmund. (1914) Introdução Ao Narcisismo, Ensaios De Metapsicologia E Outros Textos. Sigmund Freud Obras Completas. Vol. XII. São Paulo, Companhia das Letras, 2010.

FREUD, Sigmund. (1920) Além Do Princípio De Prazer. Sigmund Freud Obras Completas. Vol. XIV. São Paulo, Companhia das Letras, 2010

FREUD, Sigmund. (1924) A Dissolução do Complexo de Édipo. Edição Standard Brasileira das obras completas, vol. XIX. Rio de Janeiro: Imago, 1976.

GRAEML, Karin Sylvia. \& VOLPI, Henrique e GRAEML, Alexandre R. "O impacto do uso (excessivo) da Internet no comportamento social das pessoas". Revista Psicologia Corporal (J. H. Volpi \& S. M. Volpi, Orgs.). Vol. 5, 2004. Acessado em 27 de junho de 2017, disponível em:

https://www.researchgate.net/publication/267565787_o_impacto_do_uso_excessivo_da_inter net_no_comportamento_social_das_pessoas

Lacan, Jacques. (1949) O Estádio do Espelho como Formador da Função do Eu. In: Escritos. Rio de Janeiro: Jorge Zahar, 1998.

Lacan, Jacques. (1957) O seminário. Livro 5: as formações do inconsciente. Rio de Janeiro: Jorge Zahar, 1999. (p. 221-231)

MACHADO, Arlindo. O sujeito no Ciberespaço. XXIV Congresso Brasileiro da Comunicação - Campo Grande /MS - setembro 2001. Acessado em 02 de Outubro de 2018, disponível

em http://www.portcom.intercom.org.br/pdfs/29708550691795394214029897104174778288.pdf

MENDONÇA, Luis Henrique F. \& FANTINI, João Angelo. Adicção em Games: do cognitivo-comportamental ao estruturalismo. Memorandum, 33, 142-165. 2017. Acessado em 20 de Outubro de 2018, disponível em seer.ufmg.br/index.php/memorandum/article/view/9897

NICOLACI-DA-COSTA, Ana Maria. Revoluções tecnológicas e transformações subjetivas. Psic.: Teor. e Pesq., Brasília, v. 18, n. 2, p. 193-202, 2002. Acessado em 12 de Setembro de 2018, disponível em http://www.scielo.br/scielo.php?script=sci_arttext\&pid=S0102$37722002000200009 \& \operatorname{lng}=$ en $\&$ nrm=iso

NICOLACI-DA-COSTA, Ana Maria. Impactos psicológicos do uso de celulares: uma pesquisa exploratória com jovens brasileiros. Psic.: Teor. e Pesq., Brasília, v. 20, n. 2, p. 165 174, 2004. Acessado em 12 de Setembro de 2018, disponível em http://www.scielo.br/scielo.php?script=sci_arttext\&pid=S0102-

$37722004000200009 \& \operatorname{lng}=\mathrm{en} \& \mathrm{nrm}=\mathrm{iso}$

ORTIGARA, Alexandre Moschen. Onipotência, conceito e alguns desdobramentos. $1^{\circ}$ Simpósio de Psicologia, v.1, n.1, 2015. Acessado em 01 de julho de 2018, disponível em http://www2.pucpr.br/reol/pb/index.php/sp2015?dd1=15863\&dd99=view\&dd98=p 
PARISER, Eli. O filtro Invisível: O que a internet está escondendo de você. Rio de Janeiro: Zahar, 2012. Acessado em 04 de novembro de 2018, disponível em https://lereumvicio.files.wordpress.com/2016/06/o-filtro-invisivel-eli-pariser.pdf

PAULA, Heller. Os Baby Boomers, a Geração X, Geração Y, Geração Z e Geração Alpha. 2017. Acessado em 15 de Outubro de 2018, disponível em http://www.hellerdepaula.com.br/geracoes/

PIERRO, Bruno. (2018) O mundo mediado por algoritmos. Revista Pesquisa FAPESP, n. 266 p. $18-25,2018$.

PINTO, Manuel. A Televisão e a Família: Cruzamento de Dois Campos Movediços. Comunicar, 24, 2005. Revista cientifica de comunicación y Educación; ISSN: 1134-3478: páginas 59-67. Acessado em 16 de outubro de 2018, disponível em: https://core.ac.uk/download/pdf/60633473.pdf

PIZUTTI, Jaqueline Machado. A Constituição do Sujeito na Psicanálise. Em: Monografia Curso Psicologia, Departamento de Humanidades e Educação (DHE). Universidade Regional do Noroeste do Estado do Rio Grande do Sul (UNIJUÍ), Ijuí-RS, 2012. Acessado em 08 de julho de 2018, disponível em http://bibliodigital.unijui.edu.br:8080/xmlui/bitstream/handle/123456789/1218/Jaqueline\%20 Pizutti\%20monografia.pdf?sequence $=1$

QUINET, Antonio. Os outros em Lacan. 1. ed, Rio de Janeiro: Jorge Zahar Editor, 2012. v.1

RAMOS, Danielle Marques.; NASCIMENTO, Virgílio Gomes. A família como instituição moderna. Fractal, Rev. Psicol., Rio de Janeiro , v. 20, n. 2, p. 461-472, Dec. 2008. Acessado em 28 de Setembro de 2018, disponível em http://www.scielo.br/scielo.php?script=sci_arttext\&pid=S1984-

02922008000200012\&lng=en\&nrm=iso

Homrich, Marcele Teixeira. Alteridade e psicanálise: as modalidades de outro em Lacan. Barbarói, Santa Cruz do Sul, n.46, p.<153-165>, jan./jun. 2016. Acessado em 05 de Novembro de 2018, disponível em https://online.unisc.br/seer/index.php/barbaroi/article/view/8670

ROUDINESCO, Elisabeth \& PLON, Michel. (1997) Dicionário de psicanálise. Rio de Janeiro. Jorge Zahar, 1998.

SÁ, Gustavo Malafaya. À frente do computador: a Internet enquanto produtora de dependência e isolamento. Sociologia, 24, 133-147, 2012. Acessado em 27 de junho de 2017, disponível em: http://www.scielo.mec.pt/scielo.php?script=sci_abstract\&pid=S087234192012000200007

SETZER, Valdemar W. Efeitos negativos dos meios eletrônicos em crianças, adolescentes e adultos. 2014. Acessado em 02 de Outubro, disponível em: http://www.ime.usp.br/ vwsetzer/jokes/efeitos-negativos-meios.html

SOUZA, Elizandra R. A Linguagem e seus Efeitos na Constituição do Sujeito. In: III Simpósio Nacional Discurso, Identidade e Sociedade, 2012, Campinas. Acessado em 01 de julho de 2018, disponível em www.iel.unicamp.br/sidis/anais/pdf/SOUZA_ELIZANDRA.pdf 
SFOGGIA Ana; KOWACS Clarice. Sexualidade e novas tecnologias. Revista brasileira de psicoterapia; 16(2):4-17, 2014. Acessado em 24 de junho de 2017, disponível em: http://rbp.celg.org.br/detalhe_artigo.asp?id=150 